\title{
2.3.3 Micrometeorite Impact Craters on Skylab Experiment S 149
}

\author{
K. Nagel, H. Fechtig, E. Schneider, G. Neukum \\ Max-Planck-Institut für Kernphysik, Heidelberg, Germany
}

\begin{abstract}
During the Skylab experiment S 149 three different sets of areas were exposed. $71.5 \mathrm{~cm}^{2}$ were facing the sun for 46 days, and $36 \mathrm{~cm}^{2}$ for 33 days, whereas $77.5 \mathrm{~cm}^{2}$ were exposed in anti-solar direction for 34 days. A fourth set is currently being exposed with the hope of future recovery. The exposed surfaces consisted of stainless steel, aluminium, platinum, glass, and pyroxene. The recovered targets have been investigated with a light microscope and a scanning electron microscope. We found two groups of possible impact structures:

1.) Five craters between 1 and $30 \mu \mathrm{m}$. These craters show clear signs of hypervelocity impact. Measurements yielded diameter to depth ratios between 2 and 3 . Chemical investigations in the craters yielded an enhancement in aluminium in one case.

2.) 44 crater-like structures between 1 and $4 \mu \mathrm{m}$ in diameter. These features have been found on $4 \mathrm{~cm}^{2}$ of pyroxene exposed in solar direction. They show diameter to depth ratios between 5 and 8 . Chemical measurements of the interior of these structures indicate the elements of the pyroxene composition.

The five impacts of the first group correspond to a cumulative flux of the order of $10^{-4}\left(\mathrm{~m}^{-2} \mathrm{~s}^{-1}\right)$ for masses of about $10^{-12} \mathrm{~g}$. The second group may indicate a fragmentation process at altitudes around $450 \mathrm{~km}$. Considering these 44 crater-like structures having been produced by fragments of one projectile, the impact rate could be comparable to that calculated for the first group. If individual projectiles had produced these structures, the corresponding flux could be 2 orders of magnitude higher.
\end{abstract}

\section{Introduction}

The Skylab experiment $S 149$ was designed to measure the interplanetary dust flux near the earth (altitude approximately $430 \mathrm{~km}$ ). As a result of a kind invitation by Dr. Hemenway, Dudley observatory, Albany, N.Y., surfaces were exposed in three missions. The exposure areas consisted of stainless steel, pyroxene, phosphate glass, and foils of aluminium, and platinum. One set of $77.5 \mathrm{~cm}^{2}$ was looking for 34 days in the antisolar direction; in solar direction there has been one set of $71.5 \mathrm{~cm}^{2}$ exposed for 46 days, and another one of $36 \mathrm{~cm}^{2}$ for 33 days. Fig. 1 shows a model of the spacecraft and the position of the solar and antisolar positions.

Methods

The exposed surfaces have been scanned for micron-sized impact craters or penetration holes, respectively. All areas have been investigated 


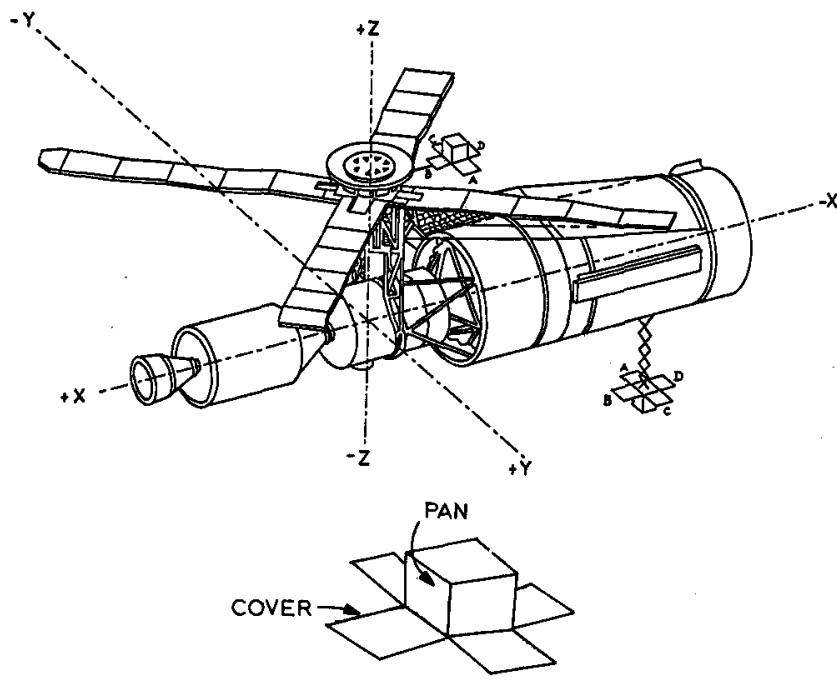

Fig. 1: Model of Skylab with the exposure positions of the collection surfaces. with a light microscope (detectable crater size $5 \mu \mathrm{m}$ diameter), and a scanning electron microscope to detect craters $.5 \mu \mathrm{m}$ in diameter. In addition, depth measurements of the individual craters have been performed. Chemical investigations in the interior of the detected craters have been done using a solid state detector $\mathrm{Si}(\mathrm{Li})$ and $X$-ray spectrometers in order to detect projectile residues.

\section{Results}

A total area of $52 \mathrm{~cm}^{2}$ has been investigated with a scanning electron microscope. Five craters have been found between $1 \mu \mathrm{m}$ and $30 \mu \mathrm{m}$ in diameter and they all show clear signs of hypervelocity impact. In Table 1, data from the five craters are listed. In addition 44 craterlike features were found on $4 \mathrm{~cm}^{2}$ of spodumen surface which are interpreted as possible fragmentation products of a low-density projectile near the collection surfaces.

Table 1: List of Impact Craters

\begin{tabular}{lccccc}
\hline Material & $\begin{array}{c}\text { Number of } \\
\text { craters }\end{array}$ & $\begin{array}{c}\text { Diameter } \\
(\mu \mathrm{m})\end{array}$ & $\begin{array}{c}\text { Diameter } \\
\text { to depth } \\
\text { ratio }\end{array}$ & $\begin{array}{l}\text { Exposure } \\
\text { direction }\end{array}$ & $\begin{array}{c}\text { Exposure } \\
\text { position }\end{array}$ \\
\hline stainless steel & 1 & 3.1 & 2 & solar & pan \\
pyroxene & 1 & 1.0 & solar & pan \\
phosphate glass & 1 & 2.0 & to & solar & pan \\
aluminium foil & 1 & 30.0 & & solar & cover \\
stainless steel & 1 & $16.0 \times 22.0$ & 3 & antisolar & pan \\
\hline pyroxene & 44 & $1.0-4.0$ & 5 & solar & cover \\
\end{tabular}


Fig. 2 shows the larger crater on stainless steel, the penetration hole in aluminium foil, and one of the 44 craters on pyroxene.

The ratios of crater diameter to crater depth of some of the 44 craters vary between 5 and 8 (Table 1). A comparison with simulated craters suggests low density projectiles (Nagel et al., 1975). If we assume that these 44 craters were produced by fragments of one
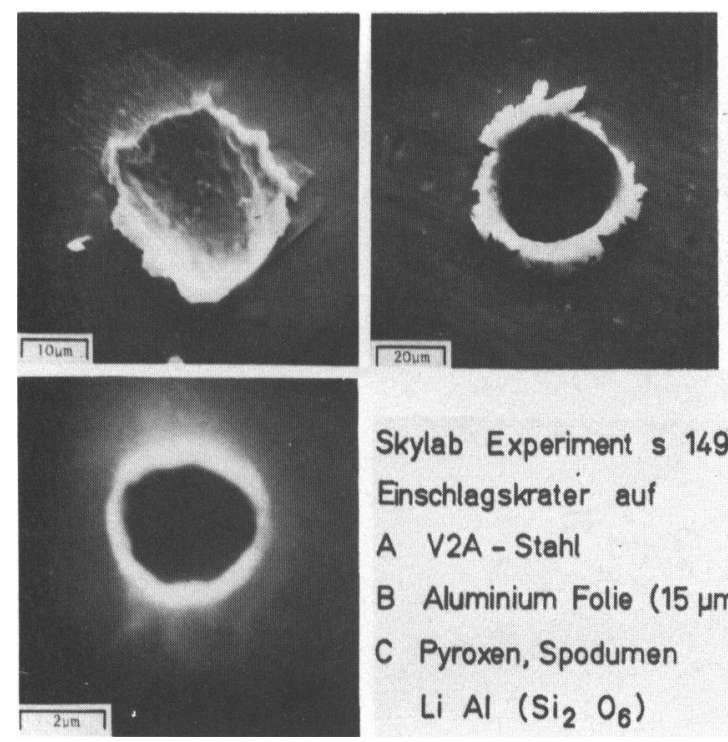

Skylab Experiment s 149 Einschlagskrater auf

A V2A - Stahl

B Aluminium Folie $(15 \mu \mathrm{m})$

C Pyroxen, Spodumen

Li Al $\left(\begin{array}{lll}\mathrm{Si}_{2} & \mathrm{O}_{6}\end{array}\right)$

Fig. 2: Scanning electron micrographs of three craters detected on exposed areas. projectile (total of 6 projectiles) the calculated particle flux is $10^{-4} \mathrm{~m}^{-2} \mathrm{~s}^{-1}$ for particle masses of about $10^{-12} \mathrm{~g}$. If we assume that each crater was produced by a primary projectile (total of 49 projectiles) the corresponding flux is two orders of magnitude higher.

Chemical measurements in some of the 44 craters yielded the pyroxene composition and no indication of other materials. Investigations of the interior of the larger crater in stainless steel showed an enhancement in aluminium. Chemical analysis of the crater in

phosphate glass revealed $\mathrm{Al}$, $\mathrm{Si}, \mathrm{P}, \mathrm{Ca}$, and $\mathrm{Fe}$, but since all these elements are present in the target it is difficult to measure the residues of the projectile if it had stony meteorite composition. However, we can still exclude the possibility that the projectile was composed of FeNi since these elements were not recorded in the crater.

\section{Discussion of results}

The results given here are in a good agreement with the results of the experiment $S 149$ of Hemenway at al. (1974).

The evidence for fragmentation processes near the collection surfaces as reported in the previous section has also been found by Hemenway et al. (1975). These fragmentation effects have been observed by the satellite experiments Prospero (Bedford et al., 1975) and HEOS 2 
(Hoffmann et al., 1975b). In a separate paper (Fechtig and Hemenway, 1976) possible fragmentation mechanisms are discussed.

The location of 4 (out of 5) craters on the pans (cf. Fig. 1, Table 1) suggests that they represent the "apex"-population of the meteoroids, since most of them are found in apex direction (Hoffmann et al., 1975a).

The results for the fluxes are also in good agreement with the results reported from the HEOS 2 dust experiment $S$ 215. The reported fluxes are close to the so-called "apex"-fluxes from the HEOS 2 results.

\section{Acknowledgments}

We like to thank Dr. C.L. Hemenway and Dr. D.S. Hallgren for the invitation to participate in their experiment $S 149$ and for their efforts in mounting and in handling our samples. Mrs. Papp has done a great part of the scanning work.

\section{References:}

Bedford, D.K., Adams, N.G., and Smith, D. (1975), "The Flux and Spatial Distribution of Micrometeoroids in the Near-Earth Environment", Planet. Space Sci. 23, 1451.

Fechtig, H., and Hemenway, C.L. (1976), "Near Earth Fragmentation of Cosmic Dust", this Volume.

Hemenway, C.L., Hallgren, D.S., and Tackett, C.D. (1974), "Near Earth Cosmic Dust Results from S-149", AIAA/AGU Conference on Scientific Experiments of Skylab, Huntsville, Alabama.

Hoffmann, H.-J., Fechtig, H., Grün, E., and Kissel, J. (1975a), "First Results of the Micrometeoroid Experiment $S 215$ on the HEOS 2 Satellite", Planet. Space Sci. 23, 215.

Hoffmann, H.-J., Fechtig, H., Grün, E., and Kissel, J. (1975b), "Temporal Fluctuations and Anisotropy of the Micrometeoroid Flux in the Earth-Moon System Measured by HEOS 2", Planet. Space Sci. 23, 981.

Nagel, K., Neukum, G., Eichhorn, G., Fechtig, H., Müller, 0., and Schneider, E. (1975), "Dependencies of Microcrater Formation on Impact Parameters", VIth Lunar Science Conference, Houston, 1975. To be published in the Proceedings of the VIth Lunar Science Conference, Vol. 3, p. 3417. 